\title{
Analysis of the Policy Driving Factors for High-Tech Industry Development
}

\author{
Bo Fan \\ School of Energy Resources ,China Univercsity of Geosciences(Beijing),Jinan, Shandong Procince,China
}

Keywords: luxury consumption; economic growth; vector auto regression; co-integration test

\begin{abstract}
With the rapid development of economy, China's luxury goods market has entered a period of rapid development. How to treat the growing luxury consumption scale, and what is the causal relationships and interactions between luxury consumption and economic growth, has become a common concern issue among scholars and the whole society. This paper acquires the data related to economic growth and luxury consumption from 1999 to 2013, taking the total consumption of luxury goods and per capita GDP as the time sequences, to establish the VAR model, and then carries out analysis on the relationship between luxury consumption and economic growth. The results show that there is a close relationship between luxury consumption and economic growth: economic growth is the reason for the consumption of luxury goods, and luxury consumption has a positive effect on economic growth, but the effect is very limited.
\end{abstract}

\section{Introduction}

With the rapid growth of China's economy and the continuous improvement of people's living standards, luxury consumption as part of consumer spending, has become an important part of stimulating economic growth. According to data statistics, by the end of 2014, China's luxury consumption has reached $\$ 106$ billion, accounting for $46 \%$ of global consumption of luxury goods, and China has become the second largest luxury consumer countries. From the viewpoint of macroeconomic policy, in the market economy, luxury goods can stimulate domestic demand and promote consumption, and it has gradually become a powerful driving force for economic development and technological progress.

From the other side, as the international financial market turbulence in recent years, currencies, stock market, bond market, futures market and commodity spot market was subject to varying degrees of impact, and thus had brought a negative impact on the economic development of many countries. However, the strong trend in the Chinese market for luxury goods consumption was barely affected by the global financial crisis.

In the past, economists and sociologists tended to focus on definition, characteristics and development of luxury goods, and the impact of luxury on the economy and society as well; nowadays, most of researches regarding luxury goods are based on consumer culture, consumer psychology, consumer structure and morality, to evaluation luxury consumption. In recent years, some scholars began to consider the economic effects of luxury goods, based on traditional western economic theory, and some scholars have put forward countermeasures and suggestions for the problems in the present stage of the luxury market, yet no one has built an econometric model to further study the mechanism of bidirectional interaction between luxury and economy. Therefore, from the viewpoint of reality and development, this paper builds an economic model to study the relationship between luxury consumption and economic growth, which is of great significance to play an active role in luxury consumption and boost China's economic growth.

\section{Model preparation}

\subsection{Data acquisition}

First of all, in terms of data acquisition, this paper selects two representative indicators of total consumption of luxury goods and per capita GDP. The total consumption of luxury goods indicates the desire and ability of consumers to purchase luxury goods; per capita GDP indicates consumers' 
wealth. We collect the time sequence data from 1999-2013. In order to get a stable sequence, we conduct logarithmic treatment on the original time sequence data, which would not change the timing characteristics of the data itself. In addition, in order to eliminate the heteroscedasticity of the time sequence data, we use the numerical value of each variable in the empirical analysis.

The specific date is shown as Fig. 1 and Fig. 2.

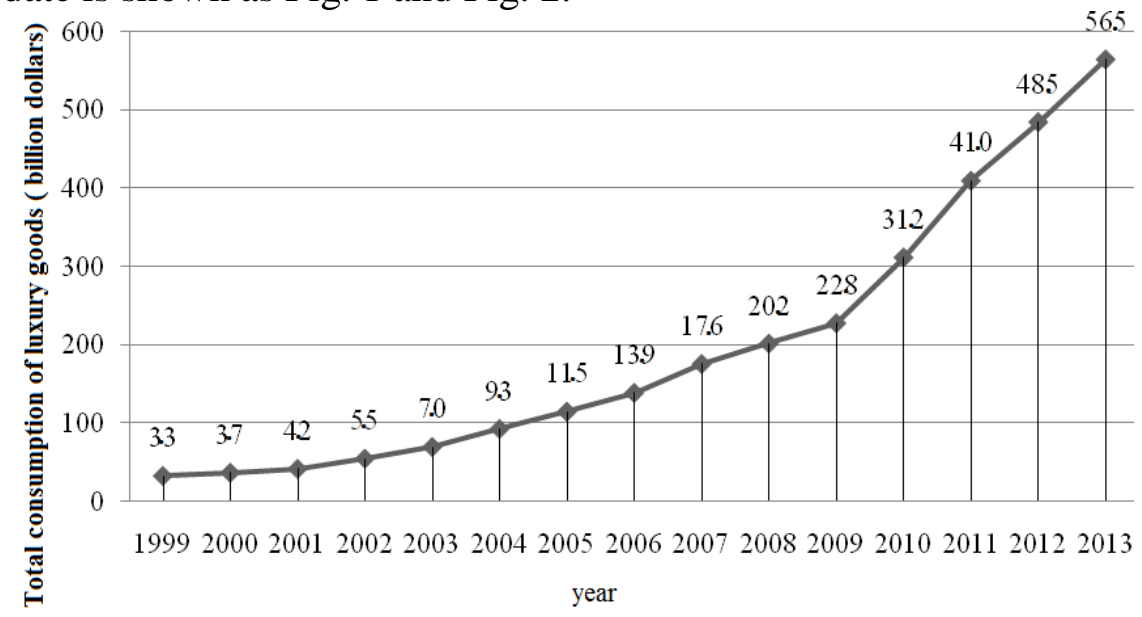

Fig.1 China’ high-end goods total consumption from 1999 to 2013

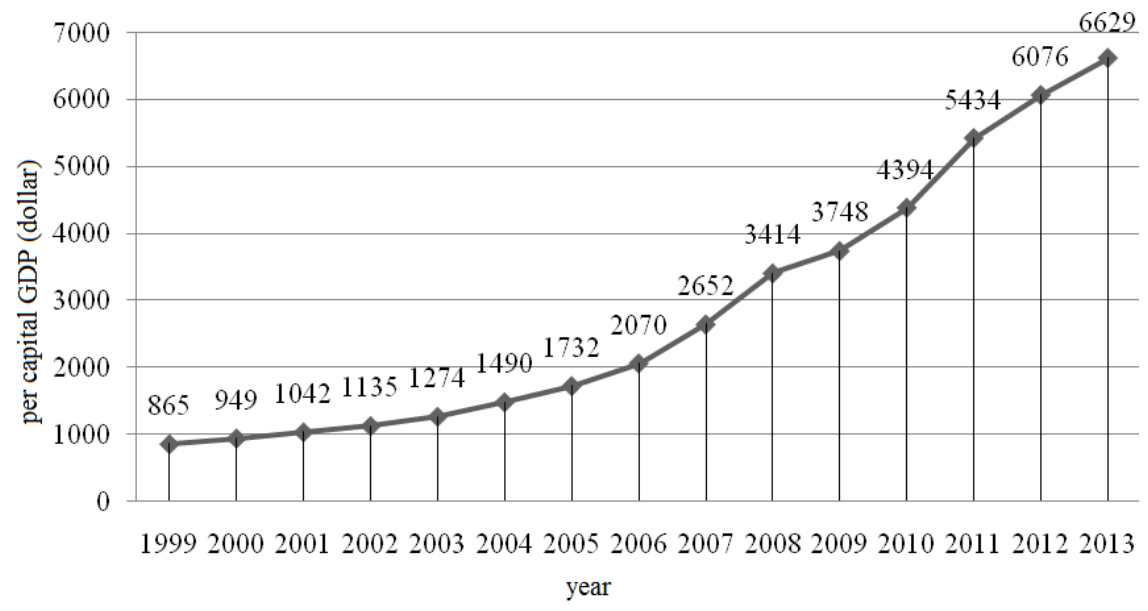

Fig.2 China’ per capita GDP from 1999 to 2013

\subsection{Model determination}

Through the preliminary judgment of the original data, we can believe that there is a link between luxury consumption and economic growth. However, in the traditional western economic theories, some studies on the relationship between luxury consumption and economic growth are often unilateral, that is, they just focus on the promoting effect of luxury consumption on economic growth, rather than their interaction effect. In this context, this paper adopt the vector auto regression (VAR) model, taking total consumption of luxury goods as the consumption indicator, and per capital GDP as the economic indicator, to demonstrate the relationship between the two time sequences of consumption indicator and economic indicator. The VAR model is as Eq. 1.

$$
y_{t}=A_{1} y_{t-1}+\cdots+A_{p} y_{t-p}+B x_{t}+\varepsilon_{t}
$$

In the equation, $y_{t}$ is endogenous variable vector; $x_{t}$ is exogenous variable vector; $A_{1}, \ldots, A_{p}$ and $B$ are Coefficient matrixes to be estimated.

\section{Model TEST}

\subsection{Unit root test}

To construct the VAR model, first of all, we need to carry out unit root test, because only with 
stationary sequence can establish the VAR model. The ADF test in unit root rest is adopted in this paper. Since the time sequence is usually not smooth, in order to avoid spurious regression due to the same trends of all the indicators, so we use ADF method to achieve unit root test on the involved variables, to verify the stability of sample sequence. To avoid heteroscedasticity, total consumption of luxury goods and per capital GDP are carried out natural logarithm processing, and are respectively named as LNGDP and LNLC. The unit root test results are shown in Tab. 1.

Tab.1 ADF unit of root test results

\begin{tabular}{|c|c|c|c|}
\hline variable & $\begin{array}{c}\text { ADF test } \\
\text { statistics }\end{array}$ & $\begin{array}{c}0.05 \text { critical } \\
\text { value }\end{array}$ & conclusion \\
\hline LNGDP & -2.215354 & -3.791172 & non-stationary \\
\hline DLNGDP & -2.189215 & -3.119910 & non-stationary \\
\hline D2LNGDP & -3.665331 & -3.144920 & stationary \\
\hline LNLC & -2.634841 & -3.791172 & non-stationary \\
\hline DLNLC & -3.019119 & -3.119910 & non-stationary \\
\hline D2LNLC & -3.699603 & -3.144920 & stationary \\
\hline
\end{tabular}

From Table 1 we can see that, LNGDP and LNLC are unstable sequence, but after second order difference, the absolute value of ADF test statistics of LNGDP is larger than the 0.05 critical value, and the absolute value of ADF test statistics of LNLC is also larger than the 0.05 critical value. So we can conclude that, although GDP and LC are unstable time sequences, they will be stable after second order difference. Therefore, the original time sequences need to conduct cointegration test.

\subsection{Co-integration test}

In order to verify whether two variables is of cointegration or not, we adopt the Johansen test method, and the test results are shown in Tab. 2.

Tab.2 Johansen test results

\begin{tabular}{|c|c|c|c|c|}
\hline $\begin{array}{c}\text { Hypothesized } \\
\text { No. of CE (s) }\end{array}$ & $\begin{array}{c}\text { Eigenvalu } \\
\mathrm{e}\end{array}$ & $\begin{array}{c}\text { Trace } \\
\text { Statistic }\end{array}$ & $\begin{array}{c}0.05 \text { Critical } \\
\text { Value }\end{array}$ & Prob. $* *$ \\
\hline None* & 0.725971 & 19.53075 & 15.49471 & 0.0116 \\
\hline At most $1^{*}$ & 0.381835 & 5.291004 & 3.841466 & 0.0214 \\
\hline
\end{tabular}

The Johansen test results show that, at the 5\% significance level, there are two cointegration vectors between the two variables of the model, so there is cointegration relationship. This proves that there is long-term and stable relationship between total consumption of luxury goods and per capital GDP, and we can continue to conduct Granger causality test before construction of VAR model.

\subsection{Granger causality test}

Although cointegration test can examine whether there is stable relationship among each variables of the non-stationary sequence, it still cannot ensure that there is a certain causal relationship between the variables. By comparison, Granger causality test is to examine whether the lag value of a variable can significantly improve the degree of interpretation of the other variable. If so, then the former variable can be regarded as Granger cause of the latter one. Therefore, to explore the causal relationship between economic growth and the consumption of luxury goods, we can adopt Granger causality test to accomplish that. The results of Granger causality test are shown in Tab. 3.

The Causality test results show that: at the $5 \%$ significant level, when lag phase is 2 or 3 , there is no causal relationship between luxury consumption and economic growth; when lag phase is 1 , economic growth is Grainger cause of luxury consumption. It indicates that, in the early stage of the development of luxury consumer market, economic growth is the cause of the consumption of 
luxury goods. However, with the increasing maturity of consumer behavior and the change of consumption concept, economic growth is no longer the cause of the consumption of luxury goods.

Tab.3 Granger causality test results

\begin{tabular}{|c|c|c|c|c|}
\hline Original hypothesis & $\begin{array}{c}\text { Lag } \\
\text { phases }\end{array}$ & $\begin{array}{c}\mathrm{F} \\
\text { Statistics }\end{array}$ & P value & Conclusion \\
\hline $\begin{array}{c}\text { Luxury consumption is not Grainger } \\
\text { cause of economic growth }\end{array}$ & 1 & 4.09504 & 0.0737 & accept \\
\hline $\begin{array}{c}\text { Economic growth is not Grainger cause } \\
\text { of luxury consumption }\end{array}$ & 1 & 6.47441 & 0.0315 & reject \\
\hline $\begin{array}{c}\text { Luxury consumption is not Grainger } \\
\text { cause of economic growth }\end{array}$ & 2 & 0.30821 & 0.7457 & accept \\
\hline $\begin{array}{c}\text { Economic growth is not Grainger cause } \\
\text { of luxury consumption }\end{array}$ & 2 & 4.24462 & 0.0710 & accept \\
\hline $\begin{array}{c}\text { Luxury consumption is not Grainger } \\
\text { cause of economic growth }\end{array}$ & 3 & 0.05075 & 0.9822 & accept \\
\hline $\begin{array}{c}\text { Economic growth is not Grainger cause } \\
\text { of luxury consumption }\end{array}$ & 3 & 1.57912 & 0.3583 & accept \\
\hline
\end{tabular}

\section{VAR model construction}

Although luxury consumption and per capital GDP are non-stationary time sequence, both of them have passed through the cointegration test, so we can construction the VAR model. Before the construction of VAR model, we still need to verify the size of the lag order, because too large or too small lag order will directly affect the effectiveness of the model parameters estimation. Determination of the lag order is shown in Tab. 4.

Tab.4 Determination of the lag order

\begin{tabular}{|c|c|c|c|c|c|c|}
\hline Lag & LogL & LR & FPE & AIC & SC & HQ \\
\hline 0 & 24.24786 & NA & $4.01 c-05$ & -4.449573 & -4.389056 & -4.515960 \\
\hline 1 & 31.20886 & $9.745398 *$ & $2.30 c-05 *$ & $\begin{array}{c}- \\
5.041772 *\end{array}$ & $\begin{array}{c}- \\
4.860221 *\end{array}$ & \begin{tabular}{c}
$5.240934 *$ \\
\hline 2
\end{tabular} \\
\hline 3 & 33.25866 & 2.049793 & $3.99 c-05$ & -4.651731 & -4.349146 & -4.983666 \\
\hline
\end{tabular}

According to AIC and SC criterion, we can obtain the lag order as 1. After determination of the lag order, we can construct the VAR (1) model, and verify the stability of the VAR(1) model, as shown in Fig. 3.

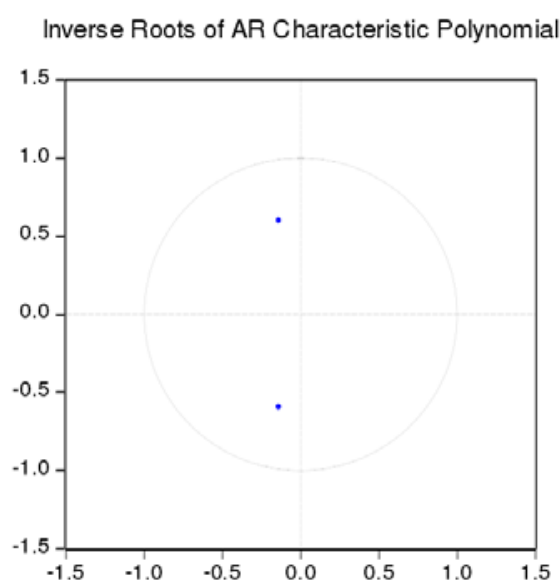

Fig.3 Characteristic root test of VAR model 
When D2LNGDP and D2LNLC are endogenous variables, the reciprocal of all roots is less than 1 , thus it can be determined that the VAR model we have established is stable.

The VAR model is difficult to explain the single parameter estimation. Since VAR model is stable, for some results, such as standard error of impulse response function, it is effective. Therefore, we make use of generalized impulse function and variance decomposition to analyze the dynamic structure of the variables.

(1) Generalized impulse response function analysis

Generalized impulse response function describes the response of an endogenous variable to a change in the magnitude of a standard deviation. Through carrying out impulse response function analysis on D2LNGDP and D2LNLC, we can obtain the response of economic growth to luxury goods consumption, and the response of luxury goods consumption to economic growth, as shown in Fig. 4.
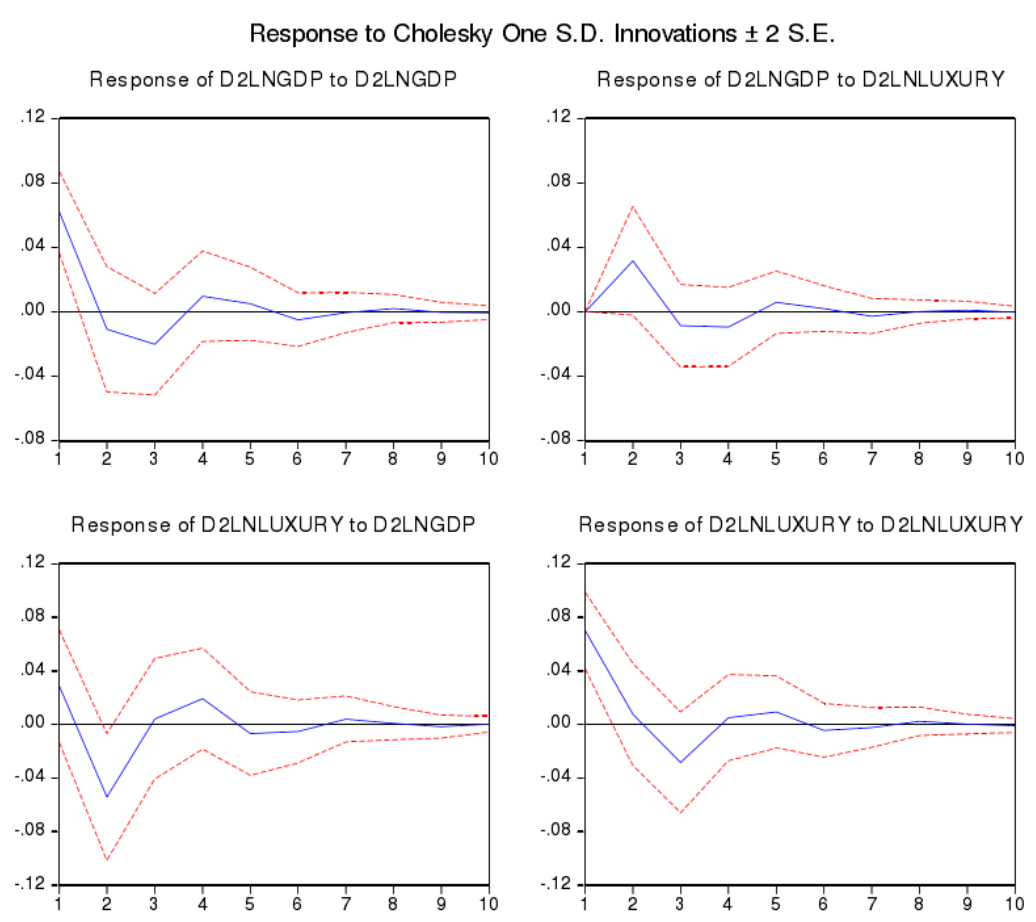

Fig.4 Generalized impulse response function

The figure in lower left corner is the response of economic growth to luxury goods consumption. It shows that after the impact of luxury goods consumption, economic growth starts with a sharp drop and even a negative value, without lag phase, which is consistent with the results of Grainger analysis. It indicates that luxury consumption is not the cause of economic growth.

The figure in upper right corner is the response of luxury goods consumption to economic growth. After the impact of economic growth, luxury goods consumption starts with an upward trend, but shows a clear downward trend later, and the succedent variation trend tends to be stable. It indicates that Economic growth will bring about the consumption of luxury goods, but when the economy grows to a certain degree, people's consumption concept and consumption behavior is becoming more and more mature, and then economic growth is no longer the cause of the consumption of luxury goods. This is also consistent with the results of Grainger analysis.

(2) Variance decomposition analysis

VAR variance decomposition is to consider the contribution level of each structural impact to endogenous variable change, and further verify the importance of different structural shocks. In this paper, that is to calculate the mutual contribution level between luxury consumption and economic growth, so as to further determine the interaction between economic growth and the consumption of luxury goods.

We can see from Table 5 that, there is little lag between economic growth and the consumption of luxury goods, and their interaction is obvious at the beginning. Average contribution rate of 
economic growth to luxury goods consumption is $38.85 \%$; average contribution rate of luxury goods consumption to economic growth is $18.73 \%$. It indicates that the average contribution of economic growth to luxury goods consumption is relatively high, which is consistent with the results of the Grainger test. In addition, this can be fully illustrated that explanatory power of economic growth to luxury consumption is relatively high, while explanatory power of luxury consumption to economic growth is low.

\section{References}

[1] Song Y T, Jing F U, Cai Y H. Luxury Consumption is an Important Manifestation of Generalized Virtual Economy_-The Status Quo of China's luxury Consumption, Trends and Development Path [J]. Research on the Generalized Virtual Economy, 2014.

[2] Pao, Hsiao-Tien, Fu, Hsin-Chia. Causal relationship between energy resources and economic growth in Brazil [J]. Energy policy, 2013.

[3] Hu Y Q. Empirical Analysis of Relationship between Information Consumption and Economic Growth [J]. Applied Mechanics \& Materials, 2014, 644-650(11):5986-5990.

[4] Silverstein. Let Them Eat Cake: Maketing Luxury to the Mass, As well as the Classes [J]. Ecological Economics, 2005, 10(9): 99-101.

[5] Dubois. Why people Buy Things They Don't Need [J]. Journal of Economics and Management, 2013, 6(11): 102-114.

[6] Beveridge S, C R Nelson. A New Approach to Decomposition of Economic Time Series into Permanent and Transitory Components with Particular Attention to Measurement of the Business Cycle [J]. Journal of Monetary Economics, 2013, 7(3): 151-174. 